\title{
Teaching Engineering Accountability through Physical Prototyping
}

\author{
Richard Retzlaff, David Torvi, Richard Burton \\ Department of Mechanical Engineering \\ University of Saskatchewan \\ rick.retzlaff@usask.ca
}

\begin{abstract}
Professional Engineers are generally accountable for the construction of a physical artifact. Therefore, an important outcome of an engineering education is to appreciate this accountability within the context of engineering design classes. To this end, the second year mechanical engineering design class at the University of Saskatchewan was modified to emphasize accountability through physical prototyping. Significant changes to the structure and facilities used in the course were required to implement this new teaching method. These included schedule changes, faculty advisor orientation, and the establishment of a five-workstation fabrication/prototyping lab. Anecdotal and survey evidence over the first three years suggests the change was a success.
\end{abstract}

Keywords: Engineering Education, Accountability, Prototypes, Fabrication, Design

\section{INTRODUCTION}

Our second year mechanical engineering design class ME229 - is a 3 credit, single term, project based class that builds on elements of the basic design process that students learn in our first year Introduction to Engineering Design class - GE121. The basic design process taught is shown in Figure 1.

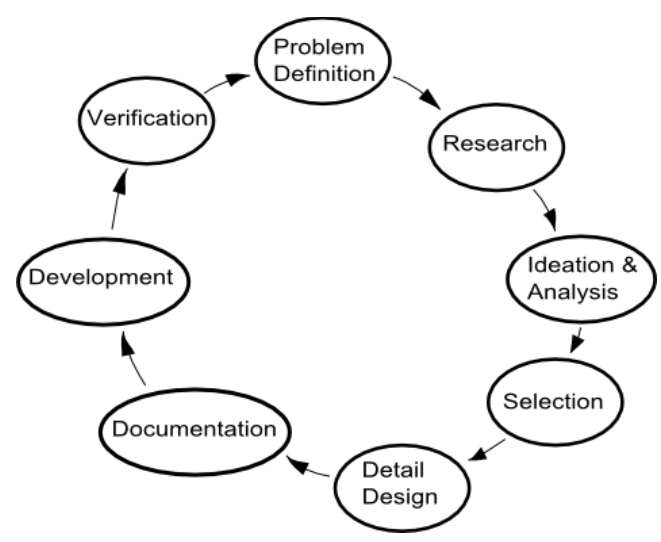

Figure 1 - The Design Process
Traditionally, our ME229 class was split into four groups, each of which was mentored by a faculty member who guided the group through the design process, rather than acting as a technical advisor. Each quarter of the class was assigned a project that was provided by a client. Clients ranged from large companies, to entrepreneurs, to faculty members in other university departments who were looking for solutions to problems they encountered in their practice (e.g., surgical tools), research or other activities (e.g., winter bicycles with improved stability). Students assigned to one of the four projects were split into groups of up to five students. Each group was responsible for interim and final reports, and made a presentation to the client, ME229 faculty members, local professional engineers and faculty members from the College of Engineering's Graham Centre (who teach our communication course).

Projects ranged in complexity and relied on theory from different areas within mechanical engineering. At this point in their program students had one year of general engineering and essentially one term of mechanical engineering experience. Although only four faculty were formally involved in the course in any year, students often consulted other ME faculty members on technical issues which in essence meant that most of the Department members were involved in the course in some form or the other.

The vast majority of designs were paper designs, with a small number of projects suitable for the development of prototypes. Typically, prototypes were only produced by some of the groups who had access to a shop. Some efforts were made to introduce prototyping using LEGO bricks or similar tools for appropriate projects.

ME229 was successful at presenting and teaching the first part of this design process. Everything up to, but not including development and verification was taught quite effectively.

Based on feedback from industry and students, as well as a review of accreditation requirements, it was decided in the fall of 2011 to try to close this design loop. The closing 
of this loop speaks specifically to "accountability in engineering design".

Accountability is a foundational principle of professional engineering. In this context, accountability is defined as the process of following through a design to the prototyping and testing stage to ensure the requirements of the problem statement are fulfilled. All through their education, students are continually reminded of the responsibility that they will need to take for their work when they move into industry after graduation. The typical completion of a design project class, including capstone courses, is a report and presentation, which is given to the industrial client, who may or may not try to implement the findings. Even if a client does implement a particular design, the students who worked on this design (or even the supervising faculty) typically are not made aware of this implementation unless they work for the company after the course ends. While there is some level of accountability in the overall process it is not the same as the expectations that will be placed on students when they move to industry, where a paper design will be manufactured or implemented.

In order to introduce this accountability within the context of this mechanical engineering design class, it was decided that the introduction of the production of a physical prototype, which would be tested and verified against project objectives, would be critical in establishing this accountability.

Physical prototyping can take on many forms. A simple demonstration model may be constructed to demonstrate the overall look and feel of a design. A proof of concept prototype can be made to demonstrate a small subset of the functionality of a design. Or, a fully working prototype can represent the total functionality of a proposed device. Within the context of this class, the prototypes developed fall into the latter category - a working model achieving all of the functions of the desired solution.

In summary, a change was needed in the way we teach design to close the design loop and thereby teaching accountability in design. It should be noted that our department is not alone in making this change to design courses. In recent years there has been a trend to return to hands-on education and physical prototyping in engineering design and manufacturing courses. One only has to walk through any engineering building constructed or renovated in the past decade to see that there has been an increased emphasis on providing space and facilities for students to work on prototypes and to gain hands-on experience.

\section{ACCREDITATION ISSUES}

The development of the ME229 course has utilized the philosophy of feedback and development which is essential in the new Canadian Engineering Accreditation Board (CEAB) outcomes approach to engineering education. Although this class has relevance for many CEAB attributes, there are two in particular that apply to accountability in engineering [1]. These are:

Attribute 10: Ethics and Equity "An ability to apply professional ethics, accountability, and equity."

We developed Program Indicator (10c), "Demonstrates accountability to stakeholders (co-workers, clients, supervisors, etc.)." This is relevant to the accountability in design that we try to teach in this class.

Attribute 5: Use of Engineering Tools "An ability to create, select, apply, adapt, and extend appropriate techniques, resources, and modern engineering tools to a range of engineering activities, from simple to complex, with an understanding of the associated limitations."

We developed Program Indicator (5d), "Evaluates the limitations of an engineering technique, resource or tool and then judges validity of the results. Fabricating and testing prototypes is an ideal method to teach the limitation of engineering analysis.

\section{THE NEW CURRICULUM}

The theme for the new curriculum for ME229 can be summarized in a single phrase:

\section{"build what you design and test what you built"}

This phrase embodies the idea of accountability in engineering. The students would be required to be accountable for their design, drawings, construction and testing.

The most important curriculum change was to implement a series of "gates" monitored and controlled (via an approval process) by our faculty advisors at certain stages of the design process. These gates included:

- problem definition statement,

- alternative designs and selection,

- working drawing preparation,

- initial testing

- revisions, and

- final performance testing. 
The faculty approval of the students' working drawings was a significant milestone. These hand-drawn, sketched working drawings were required to be of a quality suitable for submission to a machine shop for fabrication. Often, passing through this gate required multiple attempts.

Another significant milestone was the initial test. The faculty advisor would witness the first test of their fabricated prototype, witnessing the performance and making note of any changes that were required during the fabrication process.

After this first test, the students were then free to make any changes and modifications as required to improve the performance of the design.

This workflow was intended to mimic that present in a professional design office.

Significant changes were required to the structure and schedule of our class. First, a single common project was given to the students (as opposed to four in the past). This project was carefully chosen to be:

- open-ended, encouraging broad thinking,

- socially relevant, and

- conducive to building the prototype given the tools and material limitations within our lab.

Having students work on a single project also helped to address concerns over the range of background preparation that students had for the four projects the class worked on over a particular year. It also provided a larger variety of potential options to the client.

The schedule required changes to allow time in the laboratory for prototype construction. Lectures pertinent to the design process (sketching and drafting, tolerancing and dimensioning, codes and standards etc.) were frontloaded into the term to provide the needed tools for the students. More general lectures (professional practice, project management, etc.) were moved to the back of the term.

Obviously, adding this prototype requirement to the class would require borrowing time and effort from something else. In this case, the length and content of the report were reduced somewhat. Certainly, all required elements of a good engineering report were retained; however, conciseness and brevity were enforced. Actual fabrication time in the laboratory was done outside of class and tutorial hours. This did increase the student workload somewhat. However, most students found that it was a nice alternative to the more academic activities found in the rest of their classes.

\section{IMPLEMENTATION}

This new curriculum was implemented in January, 2012. One of the first tasks was to engage our faculty advisors. The role of these advisors changed somewhat in addition to helping the groups through the paper design process, they would also be observing and evaluating the students working in the fabrication lab. This was a concern because some of the advisors were involved in advanced academic research, with little experience in basic shop practice. This required some mentoring and orientation to make sure they could advise effectively.

Additionally, support from our laboratory technicians was required to set up and maintain the lab. As there is currently no dedicated space for student design projects in our current building (a building expansion is in the planning stage), space in our laboratories is always at a premium, and a lot of juggling was required to ensure the right space was available at the right time. As well, cooperation was required to deal with the inevitable mess and disruption of this type of the lab.

Safety is always a concern with students working in a lab. In our case, the students worked unsupervised during designated times (afternoon and evening sessions). A lecture in shop safety was given, and each student was required to sign a waiver indicating that they understand the safety implications and agree to the rules of the shop. Additionally, a "Safety Monitor" was assigned to each work session whose responsibility included opening up and locking down the lab, cleanup, and general oversight of the work going on. Generally, this system has worked very well. Work sessions were safe, the lab was clean and neat at the end of each session and the students had a lot of flexibility in terms of access to the lab.

The fabrication lab itself is fairly basic and straightforward. As seen in Figures 2 and 3, it consists of:

- five rolling student workstations, (each with a set of basic fabrication - oriented hand tools),

- a common cabinet containing some more sophisticated hand power tools, hardware and miscellaneous materials,

- sheet material racks,

- stick material racks,

- woodcutting bandsaw,

- stationary disk sander, and most recently,

- 32 inch laser cutter for wood and plastic. 


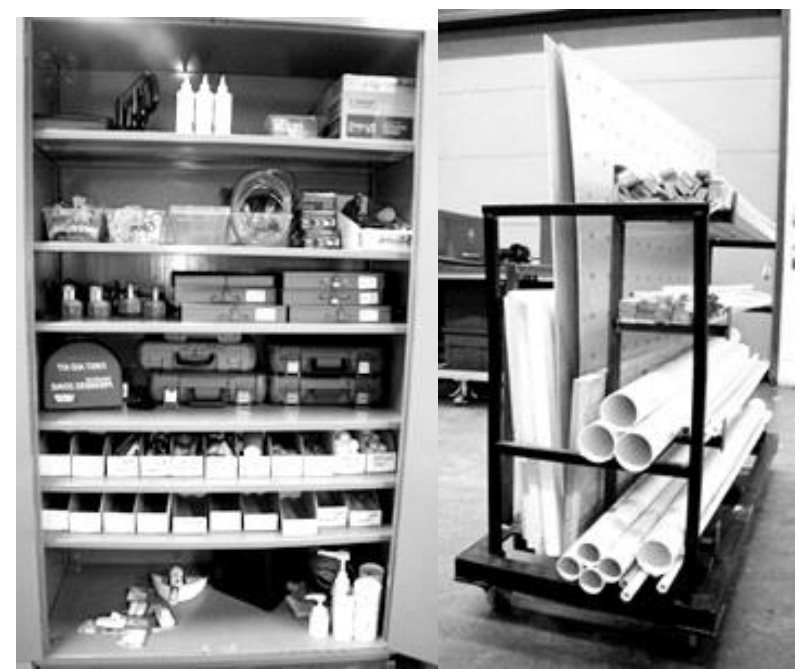

Figure 2 - Common Tool Cabinet and Material Rack

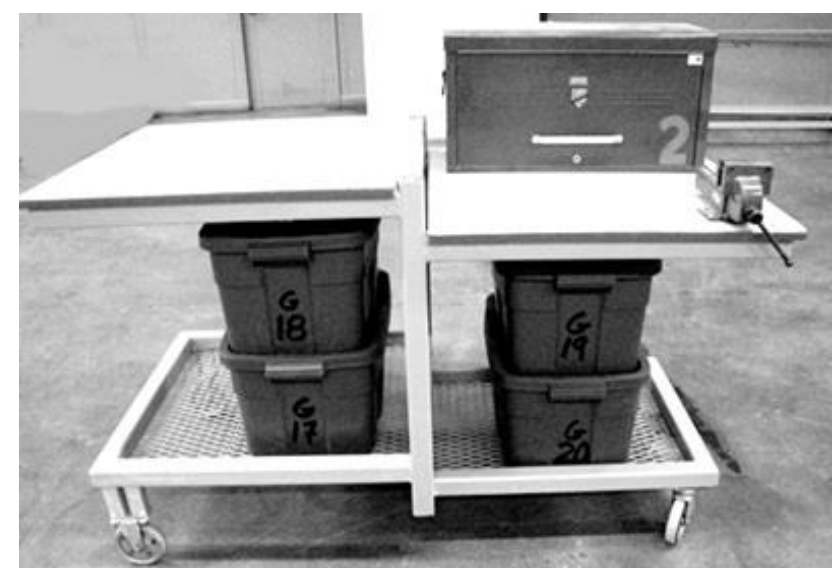

Figure 3 - Student Workstation and Storage

Due to space limitations of our existing 60's era building, the entire laboratory is mobile to make best use of the flexible space available to us. It is deployed for the three or four weeks required in February/March, and stored for the rest of the year. We were fortunate enough to have local sponsors provide much of the tools and materials as a donation. These sponsors are acknowledged at the end of the paper.

The materials stocked in the laboratory varies from year to year depending upon the project. For example, in 2014, many different types of sheet materials were included for use with our laser cutter. As well, specific hardware anticipated to be useful was stocked.

Students often complain about the limitations imposed by this set of tools. However, no matter what the sophistication of the tools available, a limitation will be imposed. In the case of our lab, the limitation is a little bit more strict than those with access to a well-equipped machine shop. However, as the emphasis in this course is to introduce the students to the concepts of prototyping and accountability in design, rather than to teach specific manufacturing techniques (which is formally introduced in upper year courses) it is felt that these tools are adequate for this purpose. It should also be noted that students come into this course with a wide variety of hands-on experience and while some would welcome more advanced tools, other students are challenged by the current set of tools and materials. It was observed that students with advanced fabrication capabilities tended to assist others with less experience.

\section{TYPICAL PROJECTS}

Suitable projects are crucial to the success of this kind of the project class. Projects must be at the correct technical level for a second-year class, require suitable analysis, and be buildable within the context of the tools and materials available in the lab.

In the first year (2012), a level control system for water in a tank was assigned. This project involved fluids, applied mechanics, material selection and basic controls and did require prototyping for testing purposes. The project, however, did not involve a "client" and so a change in direction was pursued in the following years. For the last two years, we have worked in partnership with the Tetra Society of North America [2]. This is an organization that links disabled people with very specific requirements not serviced by commercial devices with builders and engineers willing to volunteer to design and fabricate these devices.

One of the biggest advantages of working with this organization is the social awareness it brings to the projects as well as the ability to work directly with an end-user client. Typically, the client helps to introduce and set up the problem, act as a resource during the development of a solution, and attend and evaluate our final presentations.

Our first Tetra project, in 2013, was a backpack retrieval device for a client located in Vancouver. This client uses a motorized wheel chair and is not able to reach around to the back of his chair to retrieve his backpack without first moving out of his chair and then using the controls to move his chair so that he can reach his backpack. The client met with the class via a videoconference link at the beginning of the project, and visited Saskatoon for the final presentation. This project included consideration of ergonomics, kinematics, and material selection.

In 2014 the project consisted of a page turning machine for a Tetra client in Regina. This was a device intended to turn the pages of a book (based on a provided gear motor 
drive unit) autonomously. Our client was a woman with multiple sclerosis who helped us introduce the project and eagerly sat through six hours of presentations at the end of the project. This project included consideration of power and torque, kinematics, and material selection.

A key step in developing a prototype is also identifying the relevant codes and standards that the design would have to meet. Groups were required to submit this list to their faculty advisor, along with a plan for testing, based on these codes and standards. While the available materials for prototypes would not be the same as materials that would be used in a final design (e.g., some student groups used wood for prototypes of the backpack retrieval system), the prototypes did allow them to demonstrate their conceptual design to the client. Recommended materials selected for the final design could be identified in the final report, which also included analyses to size and select components of the final design.

The advisors and students have given very positive feedback on these type of projects. One particularly wellreceived part of this course was the final presentations where students demonstrated their prototype designs to the client, who provided immediate feedback. This introduced an extra level of accountability beyond the grade they obtained for the course. There was also increased interest in these presentations from local media and stories on the project presentation night were featured during the week in the local newspaper and on local newscasts.

The success of these client based projects has meant that future projects will also follow this type of approach. We will continue with these in the near future.

\section{THE RESULTS}

Two ways to evaluate the success of this implementation are to analyze our year-end class evaluations for the years previous and after implementation, as well as the collection of anecdotal evidence.

At the end of each year's class, an online evaluation is completed by the students using the university's standard course evaluation process [3]. There are two questions in particular that are relevant to the theme of this paper:

Question 1 -- "I have learned something which I consider valuable"

Question 2 -- "My interest in the subject has increased as a consequence of this course"
The students would provide an answer from 0 to 5,5 being the best. The score for the year previous to the implementation (2011), as well as the subsequent three years, is provided in Table 1. Note that previous to 2011, surveys were not completed for this class.

Table 1 - Class Survey Results

\begin{tabular}{|l|l|l|l|l|}
\hline Year & $\mathbf{2 0 1 1}$ & $\mathbf{2 0 1 2}$ & $\mathbf{2 0 1 3}$ & $\mathbf{2 0 1 4}$ \\
\hline Question 1 & 4.0 & 3.8 & 4.2 & 4.4 \\
\hline Question 2 & 3.3 & 3.7 & 3.9 & 4.1 \\
\hline Average & 3.7 & 3.8 & 4.1 & 4.3 \\
\hline
\end{tabular}

These results show a marked improvement in the perceived value and interest in the class. Although this improvement might be due to a number of factors, including the nature of the projects or the number of projects included in the class, based on talking to the students, we believe that a lot of this is attributable to the inclusion of a prototyping requirement.

In the past three years, there were no negative comments provided in the student written feedback regarding the requirement for prototyping. There were many positive comments, the following being somewhat typical:

"The design project was a challenge that came with its ups and downs but it was the most rewarding experience of my university career so far. To be able to design, draw, and build a real device for a real person with a real problem to be solved was an absolutely incredible experience."

In addition to this survey data, there is a wealth of anecdotal data directly observed during the time spent working with students in our prototyping lab. Very common quotations are:

\section{"We never thought of that" \\ "We thought this would work, but it doesn't" \\ "We really didn't think this part through very well"}

All of these comments indicate enhanced learning of the consequences of design decisions that are never obvious until actual fabrication is done.

Although these results, both numerical and anecdotal, are certainly not scientifically rigorous, we believe that implementation of our prototyping lab has benefited the students sense of value of the class, as well as their sense of professional accountability. 


\section{CONTINUING DEVELOPMENT}

We believe, in conclusion, that the introduction of hands-on prototyping in ME229 has indeed added accountability to the students' design experience. We expect over the years to increase our tools and materials selection and as such the variety and complexity of the projects can expand. In particular, a laser cutter was added to the lab this year. This was extensively used by the students, with thousands of wooden and plastic parts fabricated on this machine.

It must be emphasized that this is a second year project in which their "academic tools" are limited. A new third year design class is currently being planned that will incorporate our existing machine and manufacturing curriculum into a single project-based class with a design context. This course will provide an important bridge between this introductory second-year course and our fourth year capstone design project course, to carry forward the philosophy of accountability in design.

As well, the new CEAB outcomes approach has facilitated the development of the course. The use of attributes and indicators has facilitated assessment of group members and the use of feedback has allowed a continuous means of evaluating if the course has met its objective of providing accountability.

\section{Acknowledgements}

The following people and agencies have contributed significantly to the development of this new program:

- Mosaic Potash - funding for tools and equipment

- Shell Canada - funding for tools and equipment

- Rona Canada - donation of tools and supplies

- Bolt Supply Warehouse - donation of supplies

- Our numerous faculty advisors who have mentored students over the years.

- The faculty of the Graham Center for Communication.

- Mike Miller, laboratory technician - much help in setup and maintenance of our lab.

\section{References}

[1] Engineers Canada, Accreditation Criteria and Procedures, CEAB, 2012, ISSN 1708-8054.

[2] Tetra Society of North America, www.tetrasociety.org, Accessed April, 2014.

[3] University of Saskatchewan, Student Evaluation of Educational Quality, www.usask.ca/vpteaching/seeq/index.php, Accessed April, 2014 